\title{
Epigenetic Variation, Inheritance, and Selection in Plant Populations
}

\author{
S. Hirsch, R. Baumberger, and U. GrossnikLaus \\ Institute of Plant Biology \& Zürich-Basel Plant Science Center, \\ University of Zürich, CH-8008 Zürich, Switzerland
}

\begin{abstract}
Plant populations show phenotypic diversity, which may be caused by genetic and epigenetic variation. It has recently been shown that new epigenetic variants are generated at a higher rate than genetic variants and several studies have shown that epigenetic variation can be influenced by the environment. Although the heritability of environmentally induced epigenetic traits has gained increasing interest in past years, it is still not clear whether and to what extent induced epigenetic changes have a role in ecology and evolution. Some reports on model and nonmodel species support the possibility of adaptive epigenetic alleles, indicating that epigenetic variants are subject to natural selection. However, most of these studies rely solely on phenotypic data and no information is available about the underlying mechanisms. Thus, the role of inherited epigenetic variation for plant adaptation is unclear and further investigations are required to gain insights into the significance of epigenetic variation for ecological and evolutionary processes. Here, we review mechanisms of epigenetic regulation, epigenetic responses to environmental challenges, their inheritance, and their implication for adaptation and plant evolution.
\end{abstract}

Not too long ago, most biologists believed that all characteristics displayed by organisms were encoded in the sequence of its DNA molecule(s). In his book On the Origin of Species, Charles Darwin proposed that natural selection leads to the "preservation of favourable variations and the rejection of injurious variations" (Darwin 1859). The origin of this variation, however, was far less clear, leading Darwin to conclude that "our ignorance of the laws of variation is profound" (Darwin 1859). Since modern evolutionary synthesis, phenotypic variation is understood to stem from genetic differences among the individuals of a population (Huxley 1942). During the last two decades, however, it has become increasingly clear that mechanisms that do not affect the nucleotide sequence of the genome can cause new phenotypes. This epigenetic variation, whereby epigenetics refers to the "study of mitotically and/or meiotically heritable changes in gene expression that occur without a change in DNA sequence" (Riggs et al. 1996), contributes to phenotypic diversity in addition to genetic variation. Much of our knowledge about the mechanisms of epigenetic inheritance has been gained from studying inheritance in cell lineages within an organism, that is, addressed mitotically heritable states of gene expression. More interesting from an ecological or evolutionary perspective is the possibility that epigenetic variation may be transmitted across generations, that is, it is meiotically heritable. If an epigenetic variant, or epiallele, has a phenotypic effect and is - more or less stably - inherited to the progeny, it is referred to as an epimutant. Such epialleles contribute to the phenotypic diversity of a population and, hence, may have a role in adaptation and evolution. Moreover, the formation of certain epialleles may be triggered by the environment, as suggested in several recent plant studies
(Molinier et al. 2006; Hauben et al. 2009; Boyko et al. 2010; Kathiria et al. 2010; Lang-Mladek et al. 2010; Verhoeven and van Gurp 2012). If such effects last for several generations, the modern evolutionary synthesis will have to be expanded. Ernst Mayr proposed the concept of "soft inheritance" (Mayr and Provine 1980; Mayr 1982), whereby phenotypes can be modified by the environment and transmitted to the next generation. At the molecular level, such soft inheritance could be explained by the transgenerational inheritance of epialleles.

Although transgenerational epigenetic inheritance has attracted much interest in the scientific literature and popular press, it remains a controversial area of biology (see, e.g., Cloud 2010; Hauser et al. 2011; Paszkowski and Grossniklaus 2011; Daxinger and Whitelaw 2012; Pecinka and Mittelsten Scheid 2012). Here, we review selected studies on the origin of plant epialleles, their heritability, and the impact of the environment on the plant epigenome. We briefly describe these studies - as well as unpublished work from our laboratory on experimental and natural populations - and discuss the potential role of epigenetic variation in adaptation and, thus, their contribution to ecological and evolutionary processes.

\section{THE MOLECULAR BASIS OF EPIGENETIC VARIATION}

Epigenetic processes can stably alter transcriptional activities, and thus traits, independently of the DNA sequence. Several biochemical mechanisms that underlie epigenetic processes have been discovered that lead to changes in DNA methylation and/or histone modifications and can involve certain classes of small RNAs (Jablonka and Raz 2009; Law and Jacobsen 2010). In 
plants, DNA methylation (the addition of a methyl group to a cytosine residue resulting in 5-methylcytosine) is found in three sequence contexts: $\mathrm{CG}, \mathrm{CHG}$, and $\mathrm{CHH}$ (in which $\mathrm{H}=\mathrm{A}, \mathrm{T}, \mathrm{C}$ ). The DOMAINS REARRANGED METHYLTRANSFERASE2 (DRM2) catalyzes de novo DNA methylation in all sequence contexts and maintains asymmetric $\mathrm{CHH}$ methylation. Small RNAs target DRM2 to homologous genomic DNA sequences for cytosine methylation by the RNA-directed DNA methylation (RdDM) pathway (Henderson and Jacobsen 2007; Matzke et al. 2009). Symmetric CG methylation is maintained by METHYLTRANSFERASE1 (MET1) that recognizes hemimethylated $C G$ sites after DNA replication. The maintenance of symmetric $\mathrm{CHG}$ methylation involves the reinforcing interplay of DNA methylation and histone modifications. CHG methylation is catalyzed by the plantspecific CHROMOMETHYLASE3 (CMT3), which recognizes methylated tails of histone H3 (H3K9me2) through its chromodomain. CHG methylation, in turn, is bound by the SRA-domain of the H3K9me2 methyltransferase KRYPTONITE (KYP), leading to the reestablishment of $\mathrm{H} 3 \mathrm{~K} 9 \mathrm{me} 2$ and $\mathrm{CHG}$ methylation after each cell division. Cytosine methylation is a stable mark that is important for diverse epigenetic phenomena, including the repression of transposon activity, genomic imprinting in mammals and plants, and X-chromosome inactivation in mammals. In Arabidopsis, DNA methylation in all three sequence contexts occurs primarily at transposons and repeats, in which it is associated with $\mathrm{H} 3 \mathrm{~K} 9 \mathrm{me} 2$ and leads to transcriptional silencing (Bernatavichute et al. 2008). In addition, approximately one-third of the transcribed genes have DNA methylation, which is restricted to the GC context, in their gene bodies (Zhang et al. 2006; Zilberman et al. 2007).

Several recent reviews have classified epigenetic variants using characteristics such as origin (naturally occurring vs. environmentally induced epialleles), purity (independent vs. dependent of genetic variation), and causality (observable vs. no observable phenotype) (Hauser et al. 2011; Paszkowski and Grossniklaus 2011; Becker and Weigel 2012). A famous example of a naturally occurring, heritable epimutant is toadflax, Linaria vulgaris, in which the symmetry of the flower is changed from bilateral to radial (Cubas et al. 1999). The switch to radially symmetric flowers is correlated with DNA hypermethylation and transcriptional silencing of the $L c y c$ gene, a homolog of the cycloidea gene from the snapdragon Antirrhinum majus. The fact that no genetic mutations were found within $10 \mathrm{~kb}$ of the $L c y c$ locus indicates that the Lcyc epiallele is a pure epimutant, that is, DNA methylation is not guided by a specific DNA sequence context; however, structural genetic variation acting in trans, or in cis at some distance from $L c y c$, cannot be completely ruled out.

Further examples of naturally occurring epialleles are the Colorless nonripening ( $\mathrm{Cnr}$ ) locus in tomato (Manning et al. 2006), the transcription factor CmWIP controlling sex determination in melon (Martin et al. 2009), the FLOWERING WAGENINGEN (FWA) (Kakutani 1997; Soppe et al. 2000; Fujimoto et al. 2008, 2011) and FOLT1 loci (Durand et al. 2012) in Arabidopsis thaliana, and selected SP11 alleles at the complex $S$ locus responsible for self-incompatibility in Brassica rapa (Shiba et al. 2006; Tarutani et al. 2010). Although no changes in the underlying DNA sequence of the $L c y c$ and $C n r$ region have been observed, the epigenetic variants at $C m W I P, F W A$, FOLT1, and SP11 originate from structural genetic variation. Such structural variation can act by two distinct mechanisms that cause epigenetic changes: Transposonrelated sequences or small RNA loci can provide genetic information in cis or trans, respectively. The presence of a transposon or a transposon-derived sequence at the $C m W I P$ and FWA loci is required for the initiation and spreading of DNA methylation, leading to the silencing of these genes in cis. For instance, the silenced epiallele of CmWIP is always associated with a transposon inserted downstream from the gene from which DNA methylation spreads to the CmWIP locus (Martin et al. 2009). In contrast, FOLT1 and SP11 loci are silenced by small RNAs produced from a locus in trans, which results in DNA methylation of homologous regions by the RdDM pathway. In the case of SP11, a precursor RNA is produced from the $S m i$ locus of selected $S$ alleles and is processed into a small RNA that can direct methylation of the SP11 promoter of some $S$ alleles in trans. Thus, epigenetic silencing results in dominance of the SP11 allele of the $S$ locus that transcribes the $S m i$ gene, but silencing is only observed as long as the particular $S$-allele combination is present in the same cell (Tarutani et al. 2010). In contrast, a silenced FOLT1 epiallele, whose silencing was induced by small RNAs produced from a truncated paralogous locus in trans, can be segregated away from the inducing locus and remains silent (Durand et al. 2012).

Common to all epialleles discussed so far is that they result in a phenotype. However, because such unique epialleles that cause phenotypic changes can only be distinguished from genetic variants by in-depth molecular analyses, epigenetic alterations independent of observable phenotypes are now being analyzed at the genomewide level. Several studies in nonmodel organisms have shown by methylation-sensitive amplified polymorphism (MSAP) analyses that natural populations vary more in DNA methylation than in DNA sequence, that is, their epigenetic diversity is higher than their genetic diversity (Cervera et al. 2002; Keyte et al. 2006; Salmon et al. 2008; Herrera and Bazaga 2010; Lira-Medeiros et al. 2010). In addition, DNA methylation patterns were analyzed in Arabidopsis using high-throughput sequencing of bisulfite-treated genomic DNA (BS-Seq). The methylation patterns of two parental Arabidopsis accessions are mainly inherited by the hybrid offspring (additive methylation), with the exception of altered methylation in regions that were differentially methylated in the parents (nonadditive methylation) (Greaves et al. 2012; Shen et al. 2012). This nonadditive DNA methylation in the hybrids is associated with the action of small RNAs by the RdDM pathway.

Many of the known epigenetic alterations are attributable to the interaction among divergent alleles at the same locus or other structural genetic variation acting in cis or trans, and thus are at least partly guided by DNA sequence. 
However, spontaneous epigenetic changes that are independent of a specific sequence context have also been documented. Two recent reports describe the features of spontaneous epialleles arisen in a homogeneous Arabidopsis population during several generations (Becker et al. 2011; Schmitz et al. 2011). Both studies analyzed isogenic Arabidopsis plants derived by single-seed descent for 30 generations (Shaw et al. 2000) by BS-Seq and showed that the spontaneous loss or gain of methylation at cytosines occurs at a frequency of $\sim 1000-2000$ changes per generation, which is roughly three orders of magnitude greater than the occurrence of genetic mutations in the DNA sequence (Ossowski et al. 2010). Among the lines analyzed, this spontaneously generated epigenetic variation did not seem to have phenotypic consequences. It is thus not known whether it is subject to selection and contributes to adaptive processes.

\section{EPIGENETIC STRESS RESPONSES AND THEIR POTENTIAL INHERITANCE}

There is an increasing interest in environmentally induced epialleles, owing to their possible role in plant adaptation. As sessile organisms, plants need to adjust continuously to external stimuli and changing growth conditions. The heritability of reversible, epigenetic modifications offers an attractive possible mechanism for adaptive processes.

Environmental challenges such as stress can lead to alterations in gene expression by changes in chromatin structure at responsive genes and/or the biogenesis of small RNAs (for review, see Gutzat and Mittelsten Scheid 2012). For instance, it was shown that abiotic stress can cause the release of transgene silencing and the reactivation of endogenous heterochromatic loci in Arabidopsis (Lang-Mladek et al. 2010; Pecinka et al. 2010; TittelElmer et al. 2010). Interestingly, this stress-mediated transcriptional activation is not associated with DNA demethylation or changes in repressive histone modifications, two epigenetic marks that are characteristic for the release of transcriptional gene silencing (Lang-Mladek et al. 2010; Pecinka et al. 2010; Tittel-Elmer et al. 2010). Instead, heat stress led to a dramatic reduction in nucleosome loading and affected chromatin organization (Pecinka et al. 2010). However, the observed destabilization of transcriptional gene silencing was only of transient nature and silencing was rapidly reestablished after return to optimal growth conditions (Pecinka et al. 2010; Tittel-Elmer et al. 2010).

These and many other examples of stress-induced, epigenetic modifications only result in short-term acclimation, but for an involvement in longer lasting, heritable effects, environmentally induced alterations must be inherited. Numerous reports supposedly show that stressinduced epigenetic variation can be inherited during several generations (for review, see Boyko and Kovalchuk 2011; Gutzat and Mittelsten Scheid 2012). In stressed Nicotiana tabacum and Arabidopsis plants, as well as in their unstressed progeny, homologous recombination occurs at a higher frequency than in control plants (Molinier et al.
2006; Boyko et al. 2007, 2010; Kathiria et al. 2010). Furthermore, environmentally induced changes in DNA methylation patterns and gene expression are transmitted to unstressed offspring (Hauben et al. 2009; Verhoeven et al. 2010; Bilichak et al. 2012). In several cases, plant responses to biotic stress, such as enhanced defense reactions to herbivore and plant pathogen attacks, persist in the next generation, indicating inherited resistance (Kathiria et al. 2010; Luna et al. 2012; Rasmann et al. 2012; Slaughter et al. 2012). The transmission of stress-induced stress tolerance to the progeny was impaired when the RdDM pathway was not functional (Boyko et al. 2010; Rasmann et al. 2012). The reported results suggest that the exposure of the mother plant to biotic and abiotic stresses has an influence on its progeny. However, most of the observed responses did only persist for one generation. In addition to contributing its genome, the mother plant can influence its offspring in many other ways, for example, by depositing proteins and RNAs in the gametes, contributing metabolic and hormonal information during seed development, as well as provisioning the seed with nutrients and bioactive molecules that may signal internal and external conditions. Many of these maternal-or more generally parentaleffects will not have an epigenetic basis and should be distinguished from transgenerational epigenetic inheritance, which can be inferred only if the effects are maintained for multiple generations.

In this regard, the report that a stress-induced hyperrecombination phenotype was inherited by at least four consecutive, unstressed generations raised much interest (Molinier et al. 2006). The high frequency of intrachromosomal, homologous recombination, which has an important role in maintaining genome integrity, was triggered by exposure of Arabidopsis plants to short-wavelength radiation or the bacterial elicitor flagellin. The fact that the induced phenotype was found in several successive, untreated generations excludes a parental effect from the stressed plants. However, later experiments performed in several laboratories found that enhanced homologous recombination was limited to the immediate progeny and was not maintained in subsequent generations in the absence of stress (Boyko et al. 2010; Kathiria et al. 2010). A detailed study using the same homologous recombination reporter lines as used in the original publication found only small and stochastic changes in the frequency of homologous recombination in two generations following the stress treatment (Pecinka et al. 2009). Given these divergent results and the fact that the variation among experiments was of the same order of magnitude as the effects induced by the stress treatment, it is currently not clear whether environmentally induced epigenetic variation is transgenerationally inherited.

It is clear that epigenetic variation in plants can be induced by changes in environmental conditions. The question as to whether such induced traits are inherited to subsequent generations has been addressed in several publications. However, most studies do not exclude parental effects that are not epigenetic in nature, are not sufficiently replicated to distinguish stochastic variation among experiments from real treatment effects, and/or do not support 
their phenotypic analyses with molecular and genetic data (for review, see Paszkowski and Grossniklaus 2011; Pecinka and Mittelsten Scheid 2012). Thus, although the idea that epigenetic variation contributes to adaptation and is subject to natural selection is very appealing, more detailed studies are essential to show the transgenerational inheritance of environmentally induced epigenetic states.

\section{EPIGENETIC VARIATION IN NATURAL POPULATIONS}

Plant populations forced to adapt to different environmental conditions often show striking phenotypic adaptations. Until recently, phenotypic diversity within and among populations was thought to be attributable to genetic variation only. However, epigenetic variation may also contribute to plant adaptation and other evolutionary processes. For epigenetic variation to have an impact on the ecology and evolution of natural populations, epialleles that arise in populations must be inherited with sufficient stability.

The epialleles of $L c y c$ and $C n r$ were identified in natural populations and within agricultural fields, respectively, and have been transgenerationally inherited during several generations (Cubas et al. 1999; Manning et al. 2006). Both epigenetic variants are caused by an increase in DNA methylation at the locus, leading to transcriptional silencing of corresponding genes. That epigenetic marks can be maintained during generations is critical for a potential role in evolution. DNA methylation, in particular, in the symmetric CG and CHG contexts for which maintenance mechanisms exist, could serve as such a heritable epigenetic mark. Treatment of a set of natural Arabidopsis genotypes with the demethylating agent 5-azacytidine had a strong effect on their phenotypic plasticity, which is the ability of an organism to alter its phenotype in response to environmental changes (Bossdorf et al. 2010). Demethylation led to reduced growth and fitness and delayed flowering, indicating that DNA methylation may have a role in regulating gene expression in response to environmental stimuli, providing the basis for the alternative phenotypes displayed by the same genotype in different environments. However, 5-azacytidine is a highly toxic compound and effects other than those on DNA methylation cannot easily be excluded in such experi-ments.

Broadening the search for naturally occurring epialleles revealed variation in DNA methylation patterns in several nonmodel species living in diverse natural settings (Salmon et al. 2008; Marfil et al. 2009; Herrera and Bazaga 2010; Lira-Medeiros et al. 2010; Paun et al. 2010). In these reports, cytosine methylation polymorphisms were detected using MSAP analyses that enables the sampling of information about the methylation status across the genome without prior knowledge of the genome sequence. A recent study explored the correlation between environmental factors and epigenetic variation in Laguncularia racemosa, a mangrove tree (Lira-Medeiros et al. 2010). Laguncularia occurs in two contrasting but nearby habitats, that is, riverside and salt marsh settings. Trees growing at the riverside are large and showed a higher level of DNA methylation than smaller trees from the salt marsh. Estimating population structure revealed that epigenetic variation aligned more strongly with the habitat than did genetic variation, suggesting that specific DNA methylation patterns might be linked to environmental characteristics. Further support for a correlation of DNA methylation polymorphisms with environmental parameters comes from a study on three allotetraploid sibling orchid species of the Dactylorhiza majalis complex (Paun et al. 2010). The three closely related but phenotypically diverse orchid species showed species-specific DNA methylation patterns. Interestingly, epigenome scans showed that particular epigenetic loci that are under selection correlate with environmental parameters, such as water availability and temperature. However, although epigenetic variation, plant phenotypes, and environmental factors are correlated, no causal relationships could be shown so far.

An additional challenge to show the role of epigenetics in the above-mentioned studies is the presence of genetic variation in natural populations and their potential, unknown influence on epigenetic variation. To determine the effect of epigenetic inheritance on evolutionary processes, genetic and epigenetic variance must be independent or at least not completely dependent on each other (Richards 2008, 2011). Hence, some studies used clones that completely lack genetic variation and were either derived from apomictic lineages (Verhoeven et al. 2010) or generated by vegetative propagation (Fang and Chao 2007; Monteuuis et al. 2008). In apomictic dandelions, Taraxacum officinale, environmentally induced changes in DNA methylation can be transmitted to the progeny (Verhoeven et al. 2010). The stress treatments were associated with phenotypic effects in the progeny, but they differed among genotypes and were only partly reproducible in subsequent experiments, indicating a stochastic component (Verhoeven and van Gurp 2012).

\section{SELECTION OF EPIGENETIC VARIANTS AND THEIR ROLE IN ADAPTATION}

The development of high-throughput sequencing methods now allows the investigation of mechanistic links between genetic and epigenetic variation in plant populations. Whole-genome BS-Seq of isogenic Arabidopsis plants has not only shown that epialleles occur at a much higher frequency than genetic mutations, but also that DNA methylation sites undergo frequent reversions (Becker et al. 2011; Schmitz et al. 2011). The observed metastability of epialleles suggests that many spontaneously occurring epialleles will not be stable enough to contribute to long-term evolutionary change.

Clearly, the stability of a given epiallele is an important factor when considering the role of epigenetic variation in ecology and evolution. However, even epialleles that revert frequently will be subject to selection if they cause a phenotype. As long as the selective pressure exists, an epiallele providing a fitness advantage will be maintained 
in the population. Once the selective pressure is relieved, the epiallele may disappear within a few generations. Thus, owing to the high frequency at which it is generated, epigenetic variation could have a very important role in short-term adaptation. Moreover, the existence of environmentally induced, metastable epialleles creates meaningful phenotypic diversity, which might be both adaptive to the condition that induced them and stabilized by this condition (Herman and Sultan 2011). However, epialleles may also be highly stable, in which case they will behave just like genetic mutations in the mid- and long-term. One example of an extremely stable epiallele is the $B^{\prime}$ allele of maize. $B^{\prime}$ is an epiallele of $B-I$, which became transcriptionally silenced by paramutation in a trans-heterozygous interaction with a $B^{\prime}$ allele (for review, see Chandler and Stam 2004). In several tens of thousands of plants analyzed to date, $B^{\prime}$ was never found to revert. In addition, epialleles may become genetically assimilated, that is, stabilized by genetic mutations, in the long-term (Pál and Miklós 1999). This process is facilitated by the chemical instability of 5-methylcytosine, whose deamination forms thymine and can thus cause a transition mutation. It can be envisioned that specific epialleles may have a role in short-term adaptive processes and that they become genetically assimilated in the longer term.

Despite the potentially important role of epigenetic variation in adaptation, it has not yet been shown that epialleles are subject to selection and contribute to adaptation. We have recently combined experimental selection experiments with genome-wide BS-Seq and transcriptome studies to address this question (Heichinger et al., in prep.). A set of Arabidopsis genotypes (selected recombinant inbred lines derived from the Cape Verde Islands [Cvi] and Landsberg erecta [Ler] accessions) were tested for their response to selection in static and dynamic landscapes (Fakheran et al. 2010). Whereas in static landscapes local, nondispersed seeds were collected, in dynamic landscapes seeds dispersed at some distance from the mother plant were sampled and used to seed the next generation. Noteworthy, a strong directional selection occurred in dynamic landscapes, leading to taller, smallseeded plants after only five generations of selection (Fakheran et al. 2010). The two major genotypes that dominated the dynamic landscapes after selection, were compared by phenotypic, genomic, genome-wide BS-Seq, and transcriptome studies to their genetically identical ancestors grown in the same environment. Interestingly, flowering time and branching patterns differed significantly among genetically identical selected and ancestral lines - phenotypes that were maintained during two to three generations in the absence of selection. Although no genetic differences between ancestral and selected lines could be detected by resequencing, whole-genome BSSeq identified $\sim 5000$ differentially methylated cytosines (DMCs) that were identical in at least two independent selection experiments and, thus, likely represent selected DMCs or epialleles. These selected DMCs were overrepresented in genes associated with flowering time and plant morphogenesis, consistent with the heritable phenotypic changes that we observed. Moreover, genome-wide transcriptome studies showed that the expression of genes involved in the pathways regulating flowering time, plant growth, and epigenetic regulation differed between ancestral and selected lines and that differentially expressed genes were significantly enriched in selected DMCs. Thus, heritable changes in phenotype, cytosine methylation and gene expression correlate, indicating that epigenetic variation is under selection and contributes to the rapid adaptive responses of populations in selective environments.

\section{A ROLE FOR EPIGENETICS IN POLLINATOR SPECIFICITY?}

As described above, working with model organisms such as Arabidopsis has clear advantages, because it allows experiments in uniform genetic backgrounds and controlled environments. The advance of sequencing technologies allows a comprehensive comparison of the genomes, epigenomes, and transcriptomes of genetically identical plants that have a different history. However, to unravel the role of epigenetics in adaptation and evolution it will be essential to analyze environmental effects on the epigenome and the inheritance of epigenetic changes in plants growing in a real-world context.

In Southern California, the Diplacus (formerly Mimulus) species complex (Tulig and Nesom 2012), whose populations we have monitored for more than 15 years, may present such a real-world model (R Baumberger and U Grossniklaus, unpubl.). Coastal Diplacus puniceus plants produce red colored flowers (Fig. 1C) that are pollinated by the hummingbird Calypte anna, which has become abundant in the region during the last 50 years. Further inland, D. australis populations have yellow flowers that are pollinated by insects (Fig. 1E). Red and yellow flowers also differ in many other aspects of floral morphology, including corolla size, tube length, and position of the stigma (Fig. 1). In a specific region between these coastal and inland populations, plants producing orange flowers of intermediate morphology are found (Fig. 1D). These intermediate forms have been attributed to natural hybridization among these taxa and, because a range of interme-diate forms exist, to recurrent back crossing with one or the other parent (Streisfeld and Kohn 2005). However, by monitoring individual plants since 1995 it became clear that individuals undergo a phenotypic transition and, during the course of $12-15$ years, gradually change from producing yellow, insect-pollinated flowers to producing red, bird-pollinated flowers (Fig. 1D). As an individual maintains its genotype, this phenotypic transition must be epigenetic in nature and, because it occurs only in a specific region (transition zone, Fig. 1), the transition is likely induced by some unknown, environmental stimulus. Using crossing experiments during several generations, we have shown that the acquired epigenetic state is heritable and shows typical characteristics of an epimuation, for example, it reverts at a rate of $1 \%-2 \%(\mathrm{R}$ Baumberger and U Grossniklaus, unpubl.). Because the acquired epigenetic state affects the morphology, color, 


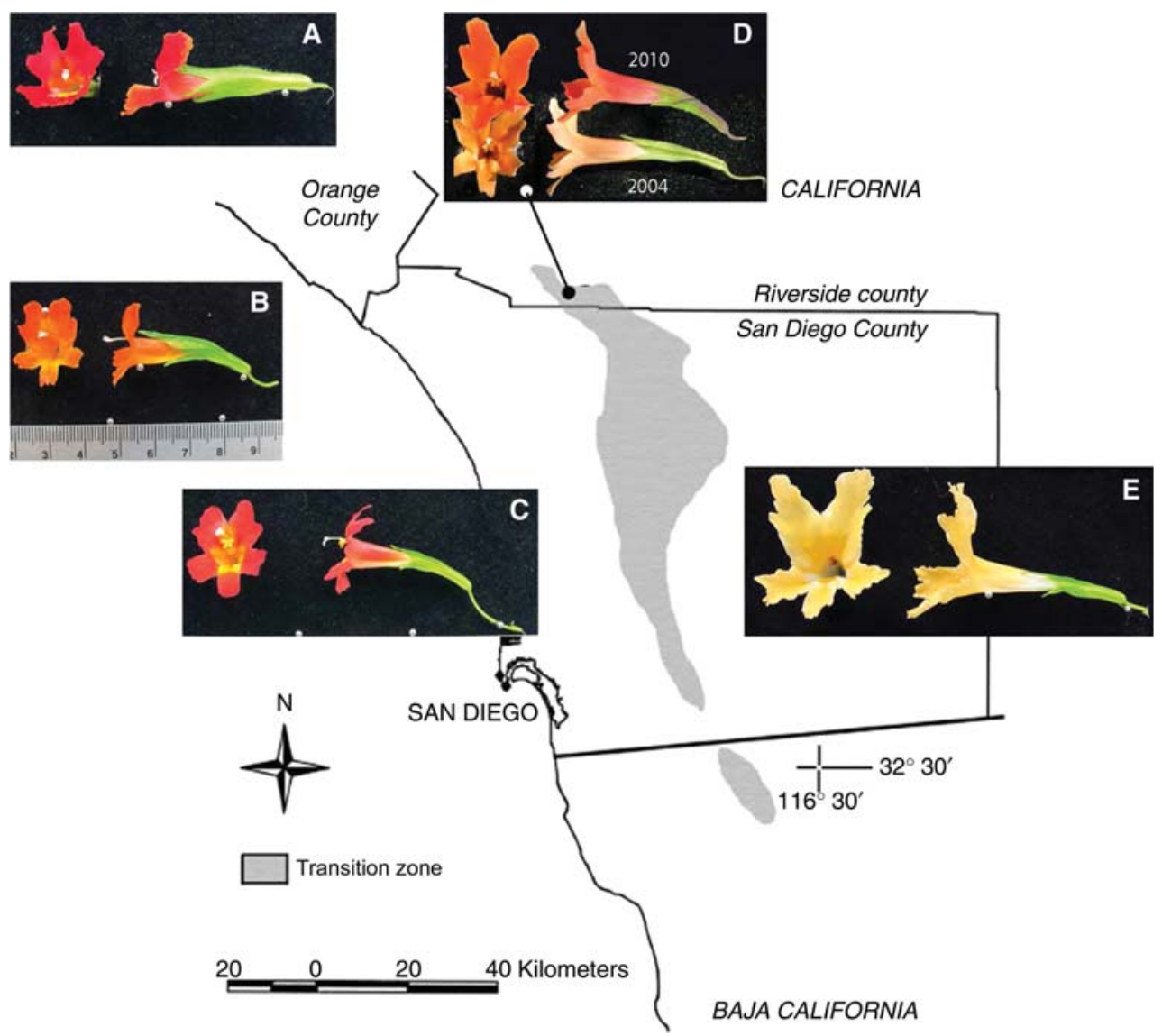

Figure 1. Distribution of various Diplacus (formerly Mimulus) species and subspecies in Southern California. (A) Dark velvet red Diplacus rutilus located at Santa Susana Pass; $(B)$ bright orange-red flowered taxon found throughout Santa Catalina Island presumably derived from $D$. australis; $(C)$ red costal $D$. puniceus west of the transition zone (indicated in gray on the map); $(D)$ individual plant in transition (flowers from the same individual in 2004 and 2010) located near the upper end of the transition zone; $(E)$ yellow $D$. australis located east of the transition zone. Transition of $D$. australis takes more than a decade until completion. Phenotypic transitions appear first near the east and north border of the transition zone within pure yellow $(D$. australis $)$ populations. Morphs shown in $B, C$, and $E$ are stable, whereas morphs in $A$ and $D$ are metastable and still in transition. All depicted flowers are shown at the same scale.

and scent of the flower and leads to reproductive isolation, it is expected to have a strong effect on population structure-including genetic and epigenetic variation-and eventually the evolutionary trajectory of these taxa.

Although we have not monitored these populations as thoroughly as those described above, nor have we performed genetic experiments, D. australis may have undergone a similar transition process on Santa Catalina Island. In 1951, producing red, orange, and yellow flowering plants were reported on the island (McMinn 1951), whereas in 2012 only red flowering plants (Fig. 1B) were found (R Baumberger, unpubl.). Moreover, populations producing small red flowers were observed at Santa Susana Pass (Fig. 1A) where previously only the large, yellow or red flowered $D$. longiflorus had been recorded (McMinn 1951). Thus, it appears that several species in the Diplacus complex have the capability to change their floral morphology by an epigenetic process that allows them to adapt to a new pollinator. The Diplacus species complex may thus present a model system that will allow us to analyze epigenetic changes and their possible role in evolution at the genetic and molecular levels in a realworld setting.

\section{CONCLUSION AND OUTLOOK}

To date, the existence of environmentally induced transgenerational epigenetic inheritance and its significance in ecology and evolution is still controversial. On one hand, certain epialleles can clearly be inherited in plants and have phenotypic effects. On the other hand, many epialleles are metastable, indicating that they might be of limited importance for ecological and evolutionary processes. The stochastic generation of epigenetic variation at relatively high frequency, however, could allow a rapid response to and be stabilized by selection. So far, most of our knowledge on epigenetic inheritance is based on studies of DNA methylation, often with material whose genetical homogeneity has not been assessed or has occurred in experiments without sufficient replication. There is a need 
for highly replicated and optimally designed experiments to generate suitable material for genome-wide studies, and the potential importance of other epigenetic mechanisms has to be explored more thoroughly. In the future, it will be interesting to comprehensively identify which epigenetic marks are modified by environmental factors and whether they are indeed transmitted to the next generation.

\section{ACKNOWLEDGMENTS}

We thank Christian Heichinger and Marc W. Schmid (University of Zürich) for allowing us to discuss their unpublished results on the selection of epigenetic variants in Arabidopsis. Our work on transgenerational epigenetic inheritance is supported by the University of Zürich, an EMBO long-term postdoctoral fellowship (to S.H.), a Syngenta-sponsored project of the Zürich-Basel Plant Science Center, and grants from the University Research Priority Program in Functional Genomics/Systems Biology and the European Research Council (to U.G.).

\section{REFERENCES}

Becker C, Weigel D. 2012. Epigenetic variation: Origin and transgenerational inheritance. Curr Opin Plant Biol 15: 562-567.

Becker C, Hagmann J, Müller J, Koenig D, Stegle O, Borgwardt K, Weigel D. 2011. Spontaneous epigenetic variation in the Arabidopsis thaliana methylome. Nature 480: 245-249.

Bernatavichute YV, Zhang X, Cokus S, Pellegrini M, Jacobsen SE. 2008. Genome-wide association of histone H3 lysine nine methylation with CHG DNA methylation in Arabidopsis thaliana. PLoS One 3: e3156.

Bilichak A, Ilnystkyy Y, Hollunder J, Kovalchuk I. 2012. The progeny of Arabidopsis thaliana plants exposed to salt exhibit changes in DNA methylation, histone modifications and gene expression. PLoS One 7: e30515.

Bossdorf O, Arcuri D, Richards CL, Pigliucci M. 2010. Experimental alteration of DNA methylation affects the phenotypic plasticity of ecologically relevant traits in Arabidopsis thaliana. Evol Ecol 24: 541-553.

Boyko A, Kovalchuk I. 2011. Genome instability and epigenetic modification-heritable responses to environmental stress? Curr Opin Plant Biol 14: 260-266.

Boyko A, Kathiria P, Zemp FJ, Yao Y, Pogribny I, Kovalchuk I. 2007. Transgenerational changes in the genome stability and methylation in pathogen-infected plants: Virus-induced plant genome instability. Nucleic Acids Res 35: 1714-1725.

Boyko A, Blevins T, Yao Y, Golubov A, Bilichak A, Ilnytskyy Y, Hollunder J, Meins F Jr, Kovalchuk I. 2010. Transgenerational adaptation of Arabidopsis to stress requires DNA methylation and the function of DICER-LIKE proteins. PLoS One 5: e9514.

Cervera MT, Ruiz-García L, Martínez-Zapater JM. 2002. Analysis of DNA methylation in Arabidopsis thaliana based on methylation-sensitive AFLP markers. Mol Genet Genomics 268: $543-552$.

Chandler VL, Stam M. 2004. Chromatin conversations: Mechanisms and implications of paramutation. Nat Rev Genet 5: $532-544$.

Cloud J. 2010. Why your DNA isn't your destiny. TIME Magazine, New York, USA.

Cubas P, Vincent C, Coen E. 1999. An epigenetic mutation responsible for natural variation in floral symmetry. Nature 401: $157-161$.

Darwin C. 1859. On the origin of species by means of natural selection, or the preservation of favoured races in the struggle for life. John Murray, London, UK.
Daxinger L, Whitelaw E. 2012. Understanding transgenerational epigenetic inheritance via the gametes in mammals. Nat Rev Genet 13: $153-162$.

Durand S, Bouche N, Perez Strand E, Loudet O, Camilleri C. 2012. Rapid establishment of genetic incompatibility through natural epigenetic variation. Curr Biol 22: 326-331.

Fakheran S, Paul-Victor C, Heichinger C, Schmid B, Grossniklaus U, Turnbull LA. 2010. Adaptation and extinction in experimentally fragmented landscapes. Proc Natl Acad Sci 107: 19120-19125.

Fang JG, Chao CT. 2007. Methylation-sensitive amplification polymorphism in date palms (Phoenix dactylifera L.) and their off-shoots. Plant Biol 9: 526-533.

Fujimoto R, Kinoshita Y, Kawabe A, Kinoshita T, Takashima K, Nordborg M, Nasrallah ME, Shimizu KK, Kudoh H, Kakutani T. 2008. Evolution and control of imprinted $F W A$ genes in the genus Arabidopsis. PLoS Genet 4: e1000048.

Fujimoto R, Sasaki T, Kudoh H, Taylor JM, Kakutani T, Dennis SE. 2011. Epigenetic variation in the FWA gene within the genus Arabidopsis. Plant J 66: 831-843.

Greaves IK, Groszmann M, Ying H, Taylor JM, Peacock WJ, Dennis ES. 2012. Trans-chromosomal methylation in Arabidopsis hybrids. Proc Natl Acad Sci 109: 3570-3575.

Gutzat R, Mittelsten Scheid O. 2012. Epigenetic responses to stress: Triple defense? Curr Opin Plant Biol 15: 568-573.

Hauben M, Haesendonckx B, Standaert E, Van Der Kelen K, Azmi A, Akpo H, Van Breusegem F, Guisez Y, Bots M, Lambert B, et al. 2009. Energy use efficiency is characterized by an epigenetic component that can be directed through artificial selection to increase yield. Proc Natl Acad Sci 106: 20109-20114.

Hauser MT, Aufsatz W, Jonak C, Luschnig C. 2011. Transgenerational epigenetic inheritance in plants. Biochim Biophys Acta 1809: 459-468.

Henderson IR, Jacobsen SE. 2007. Epigenetic inheritance in plants. Nature 447: 418-424.

Herman JJ, Sultan SE. 2011. Adaptive transgenerational plasticity in plants: Case studies, mechanisms, and implications for natural populations. Front Plant Sci 2: 102.

Herrera CM, Bazaga P. 2010. Epigenetic differentiation and relationship to adaptive genetic divergence in discrete populations of the violet Viola cazorlensis. New Phytol 187: 867-876.

Huxley J. 1942. Evolution: The modern synthesis. Allen \& Unwin, London.

Jablonka E, Raz G. 2009. Transgenerational epigenetic inheritance: Prevalence, mechanisms, and implications for the study of heredity and evolution. Q Rev Biol 84: 131-176.

Kakutani T. 1997. Genetic characterization of late-flowering traits induced by DNA hypomethylation mutation in Arabidopsis thaliana. Plant $J$ 12: $1447-1451$.

Kathiria P, Sidler C, Golubov A, Kalischuk M, Kawchuk LM, Kovalchuk I. 2010. Tobacco mosaic virus infection results in an increase in recombination frequency and resistance to viral, bacterial, and fungal pathogens in the progeny of infected tobacco plants. Plant Physiol 153: 1859-1870.

Keyte AL, Percifield R, Liu B, Wendel JF. 2006. Infraspecific DNA methylation polymorphism in cotton (Gossypium hirsutum L.). J Hered 97: 444-450.

Lang-Mladek C, Popova O, Kiok K, Berlinger M, Rakic B, Aufsatz W, Jonak C, Hauser MT, Luschnig C. 2010. Transgenerational inheritance and resetting of stress-induced loss of epigenetic gene silencing in Arabidopsis. Mol Plant 3: 594-602.

Law JA, Jacobsen SE. 2010. Establishing, maintaining and modifying DNA methylation patterns in plants and animals. Nat Rev Genet 11: 204-220.

Lira-Medeiros CF, Parisod C, Fernandes RA, Mata CS, Cardoso MA, Ferreira PC. 2010. Epigenetic variation in mangrove plants occurring in contrasting natural environment. PLoS One 5: e10326.

Luna E, Bruce TJ, Roberts MR, Flors V, Ton J. 2012. Nextgeneration systemic acquired resistance. Plant Physiol 158: $844-853$. 
Manning K, Tor M, Poole M, Hong Y, Thompson AJ, King GJ, Giovannoni JJ, Seymour GB. 2006. A naturally occurring epigenetic mutation in a gene encoding an SBP-box transcription factor inhibits tomato fruit ripening. Nat Genet 38: 948-952.

Marfil CF, Camadro EL, Masuelli RW. 2009. Phenotypic instability and epigenetic variability in a diploid potato of hybrid origin, Solanum ruiz-lealii. BMC Plant Biol 9: 21.

Martin A, Troadec C, Boualem A, Rajab M, Fernandez R, Morin H, Pitrat M, Dogimont C, Bendahmane A. 2009. A transposon-induced epigenetic change leads to sex determination in melon. Nature 461: 1135-1138.

Matzke M, Kanno T, Daxinger L, Huettel B, Matzke AJ. 2009. RNA-mediated chromatin-based silencing in plants. Curr Opin Cell Biol 21: 367-376.

Mayr E. 1982. The growth of biological thought. Harvard University Press, Cambridge, MA.

Mayr E, Provine WB. 1980. The evolutionary synthesis: Perspectives on the unification of biology. Harvard University Press, Cambridge, MA.

McMinn HE. 1951. Studies in the genus Diplacus, Scrophulariaceae. Madroño 11: 1.

Molinier J, Ries G, Zipfel C, Hohn B. 2006. Transgeneration memory of stress in plants. Nature 442: 1046-1049.

Monteuuis O, Doulbeau S, Verdeil JL. 2008. DNA methylation in different origin clonal offspring from a mature Sequoiadendron giganteum genotype. Trees 22: 779 .

Ossowski S, Schneeberger K, Lucas-Lledo JI, Warthmann N, Clark RM, Shaw RG, Weigel D, Lynch M. 2010. The rate and molecular spectrum of spontaneous mutations in Arabidopsis thaliana. Science 327: 92-94.

Pál C, Miklós M. 1999. Epigenetic inheritance, genetic assimilation and speciation. J Theor Biol 200: 19-37.

Paszkowski J, Grossniklaus U. 2011. Selected aspects of transgenerational epigenetic inheritance and resetting in plants. Curr Opin Plant Biol 14: 195-203.

Paun O, Bateman RM, Fay MF, Hedren M, Civeyrel L, Chase MW. 2010. Stable epigenetic effects impact adaptation in allopolyploid orchids (Dactylorhiza: Orchidaceae). Mol Biol Evol 27: 2465-2473.

Pecinka A, Mittelsten Scheid O. 2012. Stress-induced chromatin changes: A critical view on their heritability. Plant Cell Physiol 53: 801-808.

Pecinka A, Rosa M, Schikora A, Berlinger M, Hirt H, Luschnig C, Mittelsten Scheid O. 2009. Transgenerational stress memory is not a general response in Arabidopsis. PLoS One 4: e5202.

Pecinka A, Dinh HQ, Baubec T, Rosa M, Lettner N, Mittelsten Scheid O. 2010. Epigenetic regulation of repetitive elements is attenuated by prolonged heat stress in Arabidopsis. Plant Cell 22: $3118-3129$.

Rasmann S, De Vos M, Casteel CL, Tian D, Halitschke R, Sun JY, Agrawal AA, Felton GW, Jander G. 2012. Herbivory in the previous generation primes plants for enhanced insect resistance. Plant Physiol 158: 854-863.

Richards EJ. 2008. Population epigenetics. Curr Opin Genet Dev 18: 221-226.

Richards EJ. 2011. Natural epigenetic variation in plant species: A view from the field. Curr Opin Plant Biol 14: 204-209.
Riggs AD, Martienssen RA, Russo VEA. 1996. Introduction. In Epigenetic mechanisms of gene regulation (ed. Russo VEA, et al.), pp. 1-4. Cold Spring Harbor Laboratory Press, Cold Spring Harbor, NY.

Salmon A, Clotault J, Jenczewski E, Chable V, ManzanaresDauleux MJ. 2008. Brassica oleracea displays a high level of DNA methylation polymorphism. Plant Sci 174: 61.

Schmitz RJ, Schultz MD, Lewsey MG, O’Malley RC, Urich MA, Libiger O, Schork NJ, Ecker JR. 2011. Transgenerational epigenetic instability is a source of novel methylation variants. Science 334: 369-373.

Shaw RG, Byers DL, Darmo E. 2000. Spontaneous mutational effects on reproductive traits of Arabidopsis thaliana. Genetics 155: 369-378.

Shen H, He H, Li J, Chen W, Wang X, Guo L, Peng Z, He G, Zhong S, Qi Y, et al. 2012. Genome-wide analysis of DNA methylation and gene expression changes in two Arabidopsis ecotypes and their reciprocal hybrids. Plant Cell 24: 875892.

Shiba H, Kakizaki T, Iwano M, Tarutani Y, Watanabe M, Isogai A, Takayama S. 2006. Dominance relationships between selfincompatibility alleles controlled by DNA methylation. Nat Genet 38: 297-299.

Slaughter A, Daniel X, Flors V, Luna E, Hohn B, Mauch-Mani B. 2012. Descendants of primed Arabidopsis plants exhibit resistance to biotic stress. Plant Physiol 158: 835-843.

Soppe WJ, Jacobsen SE, Alonso-Blanco C, Jackson JP, Kakutani T, Koornneef M, Peeters AJ. 2000. The late flowering phenotype of fwa mutants is caused by gain-of-function epigenetic alleles of a homeodomain gene. Mol Cell 6: $791-802$.

Streisfeld MA, Kohn JR. 2005. Contrasting patterns of floral and molecular variation across a cline in Mimulus aurantiacus. Evolution 59: 2548-2559.

Tarutani Y, Shiba H, Iwano M, Kakizaki T, Suzuki G, Watanabe M, Isogai A, Takayama S. 2010. Trans-acting small RNA determines dominance relationships in Brassica self-incompatibility. Nature 466: 983-986.

Tittel-Elmer M, Bucher E, Broger L, Mathieu O, Paszkowski J, Vaillant I. 2010. Stress-induced activation of heterochromatic transcription. PLoS Genet 6: e1001175.

Tulig MC, Nesom GL. 2012. Taxonomic overview of Diplacus sect. Diplacus (Phrymaceae). Phytoneuron 45: 1.

Verhoeven KJ, van Gurp TP. 2012. Transgenerational effects of stress exposure on offspring phenotypes in apomictic dandelion. PLoS One 7: e38605.

Verhoeven KJ, Jansen JJ, van Dijk PJ, Biere A. 2010. Stressinduced DNA methylation changes and their heritability in asexual dandelions. New Phytol 185: 1108-1118.

Zhang X, Yazaki J, Sundaresan A, Cokus S, Chan SW, Chen H, Henderson IR, Shinn P, Pellegrini M, Jacobsen SE, Ecker JR. 2006. Genome-wide high-resolution mapping and functional analysis of DNA methylation in Arabidopsis. Cell 126: $1189-1201$.

Zilberman D, Gehring M, Tran RK, Ballinger T, Henikoff S. 2007. Genome-wide analysis of Arabidopsis thaliana DNA methylation uncovers an interdependence between methylation and transcription. Nat Genet 39: 61-69. 


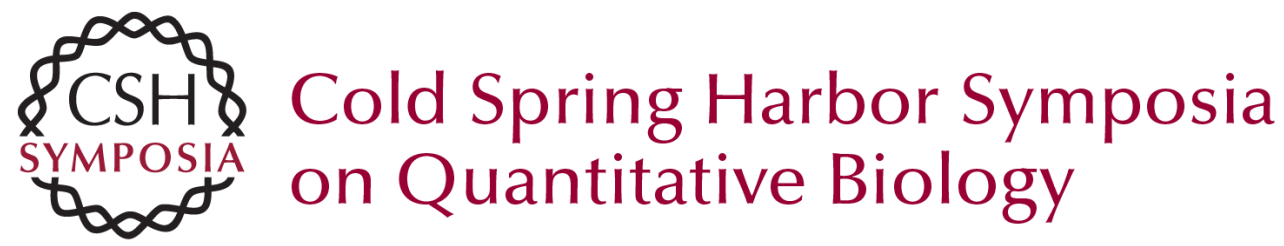

\section{Epigenetic Variation, Inheritance, and Selection in Plant Populations}

S. Hirsch, R. Baumberger and U. Grossniklaus

Cold Spring Harb Symp Quant Biol 2012 77: 97-104 originally published online April 25, 2013 Access the most recent version at doi:10.1101/sqb.2013.77.014605

References This article cites 64 articles, 12 of which can be accessed free at: http://symposium.cshlp.org/content/77/97.full.html\#ref-list-1

License

Email Alerting Receive free email alerts when new articles cite this article - sign up in Service the box at the top right corner of the article or click here. 